\title{
ESTUDO COMPARATIVO DE PROGRAMAS DE FORMAÇÃO DE PROFESSORES PARA A ESCOLARIZAÇÃO DE SURDOS (BRASIL - FRANÇA)
}

COMPARATIVE STUDY OF TEACHER TRAINING PROGRAMS FOR SCHOOLING OF THE DEAF (BRAZIL - FRANCE)

\author{
Yrlla Ribeiro de Oliveira Carneiro da Silva ${ }^{1}$ \\ ${ }^{1}$ Instituto Nacional de Educação de Surdos (INES), Rio de Janeiro, RJ, Brasil \\ yrllaribeiro22@yahoo.com.br
}

Recebido em: 25 abr. 2018

Aceito em: 21 jun. 2018

\begin{abstract}
Resumo: $O$ artigo apresenta os resultados de pesquisa de pós-doutorado realizada na Université Paris Descartes em 2017/2018. Esta teve por finalidade discutir a formação de professores para atuar na escolarização de surdos, usando como metodologia o estudo comparado entre o Brasil e a França. Nossas análises se fundamentaram em documentos legais, documentos institucionais, entrevistas e observação. Através desta pesquisa foi possível identificar e analisar as principais instituições, brasileiras e francesas que propõem uma formação de professores para atuar com surdos. Alguns aspectos se destacaram nas análises: a existência de um número pequeno de programas de formação de professores, muito aquém da necessidade desses dois países, dado o modelo de inclusão presente em ambos; o lugar que ocupa a língua de sinais nas propostas de formação, já que em algumas ela é inexistente e em outras ela é colocada como ponto crucial e a importância consagrada a temas centrais nos estudos do campo da surdez, tais como: especificidade linguística, cultura surda, identidade surda e bilinguismo, questões estas que são tratados com maior ou menor foco nas experiências estudadas. Neste artigo, optamos por apresentar apenas dois programas de formação: o primeiro de uma instituição brasileira, presente em todo o território nacional e uma instituição francesa, esta responsável pela formação dos professores da educação pública de todo o país.
\end{abstract}

Palavras-chave: Formação de Professores. Escolarização de Surdos. Estudo Comparado. Educação Inclusiva. Bilinguismo.

\begin{abstract}
The text presents the results of the postdoctoral research conducted at the Universite Paris Descartes in 2017/2018. The purpose of this study was to discuss the training of teachers who will work in the schooling of the deaf, using as a methodology the comparative study between Brazil and France. Our analyzes were based on legal documents, institutional documents, interviews and observation. Through this research it was possible to identify and analyze the main institutions, Brazilian and French, that propose a training of teachers to work with the deaf. Some aspects stood out in the analyzes: the existence of a small number of teacher training programs, much less than the need of these two countries, given the model of inclusion present in both; the place that sign language occupies in the training proposals, since in some it is non-existent and in others it is placed as a crucial point and the importance devoted to central themes in studies of the field of deafness, such as linguistic specificity, deaf culture, deaf identity, and bilingualism, which are treated with greater or lesser focus in the experiences studied. In this article we have chosen to present only two training programs: the first is developed in a Brazilian institution, present throughout the national territory, and a French institution, which is responsible for the training of public education teachers throughout the country.
\end{abstract}

Keywords: Teacher Training; Schooling Of The Deaf; Comparative Study; Inclusive Education; Bilingualism. 


\section{Introdução}

As demandas sociais dirigidas atualmente à escola exigem desta um novo projeto, outro perfil de professor, uma base formadora no paradigma da diversidade e da inclusão. Assim, a formação de professores precisa atender às exigências sociais contemporâneas, estabelecendo relações do saber docente e do saber escolar com a realidade na qual as práticas sociais se produzem.

Estudos como os de André (2009), Gatti, Barreto e André (2011), apontam que as pesquisas sobre a escola e a formação de professores cresceram muito nas últimas décadas no Brasil. Ainda segundo esses estudos, especialmente nos anos 2000, o foco dessas pesquisas recai, principalmente, no professor, nos seus saberes, nas suas práticas, nas suas opiniões e representações, o que constitui certamente um avanço positivo para se compreender melhor "os caminhos mais efetivos para alcançar um ensino de qualidade que se reverta em uma aprendizagem significativa para todos os alunos" (GATTI, BARRETO e ANDRÉ, 2011, p.15).

Cabe ressaltar que se compreende, então, a formação dos professores como um dos desafios que se apresentam, mas não o único. Nessa perspectiva, a formação dos professores não pode ser responsabilizada, de forma predominante ou exclusiva, pela qualidade do ensino público em nosso país.

Analisando os problemas referentes à formação profissional, Nóvoa (2007) destaca a necessidade de uma formação mais centrada nas práticas e na análise dessas práticas. Considera que "a formação do professor é, por vezes, excessivamente teórica, outras vezes excessivamente metodológica, mas há um déficit de práticas, de refletir sobre as práticas, de trabalhar sobre as práticas, de saber como fazer" (NÓVOA, 2007, p. 14). Explicando essa perspectiva, o autor afirma que "não é a prática que é formadora, mas sim a reflexão sobre a prática" (NÓVOA, 2007, p. 14).

Também analisando os problemas referentes à formação profissional, Zeichner (2010) aponta outro aspecto do cenário descrito por Nóvoa: a falta de conexão entre os espaços de formação, nas universidades e os espaços onde 
se realiza o trabalho docente. Essa falta de conexão é um problema recorrentemente apontado pela literatura, não somente na formação inicial, mas também na formação continuada e nas estratégias de inserção profissional, o que se constitui como um problema da formação docente que tem se perpetuado ao longo do tempo.

A formação de professores é indissociável da mudança e da intervenção na escola, mas também é necessário que a escola se engaje no processo de transformação, de apropriação e de produção de conhecimentos. Essa dialética pode ser possibilitada na dinâmica da formação de professores.

No caso da educação especial para crianças com deficiência, de forma mais geral, a literatura tem apontado que esse tipo de ensino "tem excluído, sistematicamente, grande parcela de seu alunado sob a alegação de que esta, por suas características, não possui condições para receber o mesmo nível de escolarização que as crianças que não apresentam deficiência" (BUENO, 2001, p. 4). Por outro lado, a simples inserção de alunos com necessidades educativas especiais nas escolas regulares, sem qualquer tipo de apoio ou assistência aos profissionais que ali atuam, tem redundado no fracasso escolar dessas crianças.

No que concerne a educação de surdos, podemos dizer que durante 0 período do século XVI ao século XVIII, não existiam muitos relatos sobre uma educação voltada para este público. Alguns autores como Jannuzzi (2004) e Soares (2005), relatam que existiu um médico pesquisador italiano chamado Gerolamo Cardano, que viveu no período de 1501-1576 que "concluiu que a surdez não prejudicava a aprendizagem, uma vez que os surdos poderiam aprender a escrever e assim expressar seus sentimentos" (JANNUZZI, 2004, p. 31). Outro registro importante trata de uma experiência educacional com surdos desenvolvida pelo monge beneditino Pedro Ponce de Leon (1510-1584), que atuava no mosteiro beneditino de São Salvador, em Oña, na Espanha, sendo reconhecido como o primeiro professor de surdos. Ele ensinava a linguagem articulada apenas aos filhos surdos de ricos e nobres, pois teriam que ter conhecimentos para administrarem os bens da família, garantindo sua continuidade. Silva et al (2006) ainda destacam que os surdos que não 
pertenciam à elite social da época viviam em verdadeira miséria, sofrendo a falta de trabalho e o isolamento social.

Por volta do século XVIII surgiu a educação pública dos surdos na França, num contexto de reivindicações pela igualdade social e contra privilégios.

Segundo Silva et al

Para compreender a relevância desse fato na história da educação dos surdos, é necessário perceber que a França, no século XVIII, era um verdadeiro barril de pólvora. Os levantes eram permanentes e a pequena burguesia em expansão, apoiada pelos camponeses e artesãos, não admitiam mais as benesses feudais que ainda predominavam na monarquia francesa, principalmente no Primeiro, Segundo e Terceiro Estado (2006 p.20).

A autora ressalta que o Terceiro Estado era composto pelos sem privilégio, no caso o povo, que incluíam os artesãos, os camponeses e os surdos também faziam parte deste grupo.

Manacorda (1999, apud SILVA et al 2006, p.249) relata que, na segunda metade do século XVIII, "a nova produção de fábrica gera o espaço para o surgimento da moderna instituição escolar pública. Fábrica e escola nascem juntas". E é justamente na França, neste período que se dá a criação da primeira Escola Pública para Surdos em Paris. O Abade Charles-Michel de L'Epée'1, que considerava importante a língua de sinais na educação de surdos, fundou a primeira escola público para surdos e mudos de Paris.

Sacks (1998) refere-se ao Abade L'Epée como um monge humilde que se fundamentou na língua de sinais dos surdos pobres que vagavam por Paris, para compor seu método de educação de surdos chamado de Sinais Metódicos ou gestualismo (uma combinação de língua de sinais nativa com a gramática francesa).

Skliar (2000) relata que o abade L'Epée costumava fazer demonstrações públicas anuais para mostrar a importância de seu método, para sensibilizar a comunidade parisiense. E que após cinco ou seis anos de formação na escola, os surdos dominavam a língua francesa e outros conhecimentos gerais.

\footnotetext{
${ }_{1}^{1}$ Abade Charles-Michel de l'Épée (Versalhes, 25 de novembro de 1712, em Versailles - Paris, 23 de dezembro de 1789) foi um educador filantrópico francês do século XVIII, que ficou conhecido como "Pai dos surdos".
}

Pensares em Revista, São Gonçalo-RJ, n. 12, p. 30-55, 2018 
Em 1790, um ano após a morte de L'Epée, a escola transformou-se no Instituto Nacional para Surdos-Mudos de Paris, mais ao longo deste período vinte e uma escolas para surdos já haviam sido criadas na França e na Europa.

Antes do Congresso de Milão (1880) existiam duas tendências para a educação de surdos: O gestualismo (método francês) criado pelo Abade L'Epée (como já dito acima) e o oralismo² (método alemão) criado por Samuel Heinicke.

Com o avanço dos estudos e da divulgação das práticas pedagógicas com surdos, ocorreram dois grandes Congressos: o primeiro ocorrido em Paris em 1788, onde os surdos tiveram algumas conquistas importantes, como o direito a assinar documentos, tirando-os da "marginalidade" social, mas ainda estava distante a possibilidade de uma verdadeira integração social. E o segundo em 1880, quando houve o Congresso Mundial de Professores de Surdos, em Milão, na Itália, que durou três dias. Foram votadas oito resoluções. Uma delas foi votada com unanimidade, a que dizia que os governos deveriam tomar medidas para que todos os surdos recebessem educação. Conclui-se que todos os surdos deveriam ser ensinados pelo Método Oral Puro ${ }^{3}$.

Segundo Silva et al,

Nesse Congresso, que no momento da deliberação não contava com a participação nem com a opinião da minoria interessada -os surdos -, um grupo de ouvintes impôs a superioridade da língua oral sobre a língua de sinais e decretou que a primeira deveria constituir o único objetivo do ensino (2006, p.26).

Para Skliar (1997), as razões que sustentavam a aprovação do método oral, eliminando a utilização da língua de sinais, estavam vinculadas as questões políticas, filosóficas e religiosas. Ainda de acordo com Silva et al (2006), a atribuição do fracasso da educação pública para surdos por meio da língua de sinais, não poderia ser justificada, pois a mesma estava alcançando os seus objetivos e não tinha necessidade de ser modificada. Após o Congresso de Milão, as práticas educacionais foram vinculadas ao Oralismo, que vigorou na educação do aluno surdo por um longo período (por quase um século).

\footnotetext{
2 É um método que reúne um conjunto de procedimentos terapêuticos que tem por objetivo a aprendizagem da língua oral.

${ }^{3}$ Este método determinava que o surdo só poderia usar a leitura labial e a língua escrita.
} 
Por volta dos anos 1960, por meio de resultados de pesquisas, constatase o fracasso acadêmico sofrido pelo surdo e de acordo com Sacks (1998, p.45), "o Oralismo e a supressão do sinal resultaram numa deterioração dramática das conquistas educacionais das crianças surdas e no grau de instrução do surdo em geral". E ainda, segundo Dias (2006), tornou-se evidente, através de pesquisas realizadas sobre a Língua de Sinais, que o aprendizado desta língua ajudava o desenvolvimento escolar das crianças surdas.

Nesta mesma década, começaram a surgir estudos sobre as línguas de sinais utilizadas pelas comunidades surdas, sendo representativa a pesquisa realizada por Willian C. Stokoe (1960). Apesar da proibição dos oralistas ao uso de gestos e sinais, raramente se encontrava uma escola ou instituição para surdos que não tivesse desenvolvido, às margens do sistema, um modo próprio de comunicação através de sinais.

$\mathrm{Na}$ década de 1970, a insatisfação com o oralismo e as pesquisas sobre línguas de sinais deram origem a novas propostas pedagógico-educacionais em relação à educação da pessoa surda. A Comunicação Total - método de ensino que se utiliza de todas as formas de comunicação, incluindo língua de sinais, alfabeto manual, leitura da fala, leitura labial, desenho e escrita - surge como um método alternativo, embora, na prática, alguns professores utilizarem-na ainda de maneira incipiente com seus alunos.

Uma das críticas feitas à Comunicação Total remonta ao fato de não ser possível efetuar a transliteração de uma língua falada em sinal, palavra por palavra, ou frase por frase, pois as estruturas são essencialmente diferentes. Desta forma é impossível preservar as estruturas das duas línguas ao mesmo tempo.

Surge, na década de 1980, outra proposta educativa como fruto de pesquisas sobre a educação de surdos, sobre a língua de sinais e sobre as comunidades surdas (CAMPELLO e REZENDE, 2014). A educação bilíngue considera a língua de sinais como a natural do surdo, por ser uma língua de natureza visual-motora, canal de maior apreensão destes sujeitos, sendo aprendida de forma espontânea no contato com outros surdos em curto tempo 
e, por ser através dela que os surdos conseguem se expressar com clareza. (PEDREIRA, 2008)

Neste modelo a proposta é que os alunos surdos aprendam duas línguas, considera-se a língua de sinais como primeira língua e a língua majoritária dos ouvintes, como segunda língua, desenvolvida através da leitura e da escrita, entendida como uma língua instrumental.

Introduzida, no Brasil, na década de 1990, a educação bilíngue para surdos vem se desenvolvendo de forma incipiente, a partir da introdução de intérpretes de LIBRAS, responsáveis pela mediação entre surdos e ouvintes (PEDREIRA, 2008). De fato, a inserção do professor na educação de surdos tem se dado de forma conflituosa mais do que o normal $e$ isso se deve essencialmente a falta de preparo dos docentes para lidar com as diferenças no espaço escolar (NASCIMENTO e COSTA, 2014).

Na França, em 1991, uma lei evoca a noção de educação bilíngue, mas é através de uma lei de 2005, que trata da inclusão, que esta questão se torna mais presente no cenário nacional francês. Vários estudos demonstram (BERTIN, 2007; GEFFROY e LE ROUX, 2016) que ainda são poucos os espaços de educação bilíngue para surdos. No espaço escolar ordinário não há presença de intérprete e os professores ainda se ressentem pela falta de formação para trabalhar com estes alunos.

De fato, o receio da exclusão dentro da proposta da inclusão nos levou a crer que uma perspectiva bilíngue intercultural de formação de professores é necessária e, até o momento, revela-se como a mais adequada à formação de professores para a educação de surdos. De acordo com as pesquisas mencionadas, a inclusão de surdos numa perspectiva bilíngue ainda não contemplou o diálogo entre as diferenças e ainda não possibilitou o empoderamento dos surdos e a disseminação de sua cultura no ambiente escolar, a ponto de considerar suas especificidades culturais e identitárias no espaço escolar, para além da língua de sinais, o que os mantêm, infelizmente, excluídos na inclusão. Também é importante que se materialize uma mudança, no que tange às representações sobre a pessoa surda e a surdez (WALSH, 2009; PEDREIRA, 2006; CAMPELLO e REZENDE, 2014). 
A literatura tem apontado ainda a falta de uma política de formação de professores, quer para a atuação no ensino regular, quer para o ensino especial. Se, por um lado, sabemos que grande parte dos professores do ensino regular não possui preparo mínimo para trabalhar com crianças que apresentem deficiências evidentes, por outro lado, observamos que a formação dos professores para o ensino especial está centralizada na minimização dos efeitos específicos das mais variadas deficiências (BUENO, 2001).

No caso da formação de professores, especificamente para atuar na educação de alunos surdos, percebemos que os docentes reclamam da carência de apoio institucional, na busca de formação e aprimoramento profissional, e da dificuldade de estabelecer um trabalho efetivamente bilíngue nas disciplinas escolares. Nesse aspecto, há evidente dificuldade de compreensão conceitual, por parte dos professores, sobre o significado da perspectiva bilíngue na educação de surdos que pode derivar de uma fragilidade em sua representação da surdez como diferença (ANTUNES e NASCIMENTO, 2011).

Assim, nesta pesquisa analisamos como os programas de formação de professores vêm se organizando para atender as principais demandas para a formação de um professor que seja capaz de enxergar, analisar, criticar e vivenciar o processo pedagógico de forma ampla e abrangente, mas também na especificidade atinente à educação de surdos.

Esta pesquisa se desenvolve no âmbito dos recentes movimentos que têm ocorrido no sentido da implementação de uma política para a educação especial no Brasil. No texto da Política Nacional de Educação Especial na Perspectiva da Educação Inclusiva (2008), registra-se que a formação do professor para atuar na modalidade de educação especial deve ser realizada em cursos de graduação, pós-graduação e formação continuada, seguindo as Diretrizes Curriculares Nacionais para a formação inicial em nível superior (cursos de licenciatura, cursos de formação pedagógica para graduados e cursos de segunda licenciatura) e para a formação continuada (Resolução

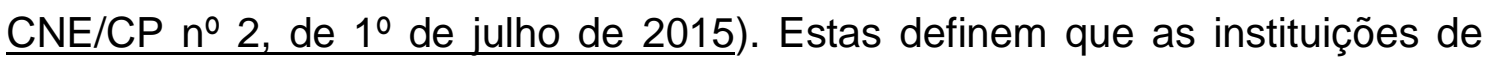
ensino superior devem prever em sua organização curricular formação docente voltada para a atenção à diversidade e que contemple conhecimentos sobre as 
especificidades dos alunos. No que se refere à educação de surdos, destaca-se a publicação da "Lei de Libras" (Lei no 10.436/2002) e do Decreto da Presidência da República no 5.626, de 22 de dezembro de 2005 que a regulamenta e que se tornou um marco por ser o primeiro documento a falar de uma formação de professores específica para atuar na escolarização de surdos. E, ainda, visando a implementação da formação destes professores, o governo federal, através do Programa Viver sem Limite (Decreto ํㅜ 7612/2011), apontou para a criação de 12 cursos de Pedagogia bilíngues em todo o Brasil ${ }^{4}$.

No caso francês, a formação de professores da Educação Nacional (escolas públicas) para trabalhar com alunos surdos começa em 2005, decorrente da lei $n^{\circ}$ 2005-102, de 11 de fevereiro de 2005 que regulamenta sobre a igualdade de direitos e de chances, a participação e a cidadania das pessoas deficientes; através da formação oferecida pelo INS-HEA. Mas, desde os anos 1990, uma formação já era ofertada aos portadores do diploma de Licence pelo Centre National de Formation des Enseignants intervenant auprès des jeunes déficients sensoriels (CNFEDS), com duração de 2 anos, visando preparar para o certificado de aptidão para professores de jovens surdos (CAPEJS). Estas duas formações não dialogam visto que uma é vinculada ao Ministério da Educação e outra ao Ministério da Saúde.

Esta pesquisa se desenvolve no âmbito dos recentes movimentos que têm ocorrido no sentido da implementação de uma política para a educação especial no Brasil. No texto da Política Nacional de Educação Especial na Perspectiva da Educação Inclusiva (2008), registra-se que a formação do professor para atuar na modalidade de educação especial deve ser realizada em cursos de graduação, pós-graduação e formação continuada, seguindo as Diretrizes Curriculares Nacionais para a formação inicial em nível superior (cursos de licenciatura, cursos de formação pedagógica para graduados e cursos de segunda licenciatura) e para a formação continuada (Resolução $\mathrm{CNE} / \mathrm{CP} \mathrm{n}^{0}$ 2, de 1을 de julho de 2015). Estas definem que as instituições de

\footnotetext{
${ }^{4}$ Estes cursos estão sendo implementados através da modalidade educação à distância, pelo INES, a partir de 2018.
} 
ensino superior devem prever em sua organização curricular formação docente voltada para a atenção à diversidade e que contemple conhecimentos sobre as especificidades dos alunos. No que se refere à educação de surdos, destaca-se a publicação da "Lei de Libras" (Lei oㅜ 10.436/2002) e do Decreto da Presidência da República oㅜ 5.626, de 22 de dezembro de 2005 que a regulamenta e que se tornou um marco por ser o primeiro documento a falar de uma formação de professores específica para atuar na escolarização de surdos. E, ainda, visando a implementação da formação destes professores, o governo federal, através do Programa Viver sem Limite (Decreto № 7612/2011), apontou para a criação de 12 cursos de Pedagogia bilíngues em todo o Brasil $^{5}$.

No caso francês, a formação de professores da Educação Nacional (escolas públicas) para trabalhar com alunos surdos começa em 2005, decorrente da lei $n^{\circ}$ 2005-102, de 11 de fevereiro de 2005 que regulamenta sobre a igualdade de direitos e de chances, a participação e a cidadania das pessoas deficientes; através da formação oferecida pelo INS-HEA. Mas, desde os anos 1990, uma formação já era ofertada aos portadores do diploma de Licence pelo Centre National de Formation des Enseignants intervenant auprès des jeunes déficients sensoriels (CNFEDS), com duração de 2 anos, visando preparar para o certificado de aptidão para professores de jovens surdos (CAPEJS). Estas duas formações não dialogam visto que uma é vinculada ao Ministério da Educação e outra ao Ministério da Saúde.

\section{Os programas de formação}

\section{Instituto Nacional de Educação de Surdos (INES) - Brasil}

O Curso Bilíngue de Pedagogia do INES teve sua origem fortemente vinculada ao reconhecimento por lei da Língua Brasileira de Sinais (LIBRAS) no ano de 2002, que culminou na publicação do Decreto da Presidência da

\footnotetext{
${ }^{5}$ Estes cursos estão sendo implementados através da modalidade educação à distância, pelo INES, a partir de 2018.
}

Pensares em Revista, São Gonçalo-RJ, n. 12, p. 30-55, 2018 
República № 5.626, de 22 de dezembro de 2005. Este decreto aponta para a formação de professores em seu artigo 5ㅜ, quando determina que:

/.../ a formação de docentes para o ensino de LIBRAS na educação infantil e nos anos iniciais do ensino fundamental deve ser realizada em Curso de Pedagogia ou Curso Normal Superior, em que LIBRAS e Língua Portuguesa escrita tenham constituído línguas de instrução, viabilizando a formação bilíngue.

Em 2005, uma portaria do Ministério da Educação autorizou o INES a ofertar o Curso Normal Superior - Licenciatura visando à formação de professores/as para atuação na Educação Infantil e nos anos iniciais do Ensino Fundamental. Nessa mesma data, o Ministro da Educação, Professor Fernando Haddad, visitou o INES e inaugurou o prédio destinado ao Ensino Superior.

Sendo assim, no primeiro semestre de 2006, o INES passou a ofertar duas turmas de 30 estudantes cada, nos turnos diurno e noturno, do Curso Normal Superior. Este curso objetivava promover a formação, a qualificação e a educação continuada em uma perspectiva bilíngue, formando profissionais com competência científica, social, política e técnica, habilitados à eficiente atuação profissional.

Mais tarde, no entanto, a Resolução CNE/CP no 01/2006, em seu art. 11, permitiu a transformação dos Cursos Normais Superiores em Cursos de Pedagogia, através da elaboração e apresentação de um novo projeto pedagógico.

Tal proposta de transformação elaborada pelo INES possuía, conforme Franco (2009, p. 22), "a grande tarefa de representar, de fato, a possibilidade de exercício da diferença da comunidade surda brasileira". A autorização do MEC, que transformou o curso em "Pedagogia - Licenciatura" deu-se através da Portaria n. 942, de 22 de novembro de 2006.

Este curso era oferecido em 8 semestres e comportava 3480 horas, dentre elas 380 horas de estágio.

O objetivo original do curso era mesmo formar o professor de surdos. Como tal, a estrutura curricular dispôs de atividades formadoras que qualificassem este pedagogo para atuar na docência com alunos surdos. Assim, 
entre as atividades curriculares, destacam-se muitas disciplinas que abordam, ora de forma exclusiva, ora de forma transversal, conteúdos próprios à formação deste profissional.

Ao analisar a grade curricular e os programas das disciplinas podemos arriscar dizer que, visto que nem sempre o programa retrata fielmente o que é trabalhado em sala de aula, $40 \%$ das disciplinas oferecidas estão voltadas especificamente ou em mais de $50 \%$ de seus programas para formação de professores para atuar na educação de surdos ${ }^{6}$. Este número nos leva a algumas reflexões, já muito bem apresentadas e discutidas por Cruz (2016) ${ }^{7}$. Dentre elas a inexistência da disciplina de LIBRAS e de disciplinas com abordagem clínica da surdez.

Os pesquisadores da área da surdez no campo das ciências humanas já vinham apontando para este distanciamento da área clínica e enfatizando os contextos culturais, identitários e linguísticos da pessoa surda. Entender a surdez como uma diferença linguística foi o primeiro passo para a luta do reconhecimento da LIBRAS como língua. Como o curso é, em parte, oriundo desta luta, nada mais coerente do que focar a formação nos aspectos linguísticos, culturais, identitários e didático-pedagógicos da formação de professores.

A Instituição ainda apresenta um setor clínico muito forte, com um grande quadro de fonoaudiólogos, que desenvolvem um trabalho clínico de aquisição da fala com as crianças da pequena infância. Contradições existentes no espaço de formação deixaram o curso isento de um olhar clínico sobre a formação de professores. $^{8}$

A inexistência da disciplina de LIBRAS pode ser justificada pela précondição de acesso, uma vez que essa é a língua de instrução do curso.. Sendo assim, todos os inscritos no processo seletivo passam por um rigoroso teste de

\footnotetext{
${ }^{6}$ Deste número de disciplinas analisadas estão excluídas as quatro disciplinas de estágio, pois estas precisam acompanhar as áreas de atuação do pedagogo previstas em Lei e as duas disciplinas de orientação de monografia, visto que o tema é de livre escolha dos alunos e nem sempre versam sobre a surdez.

${ }^{7}$ Apesar de não termos a mesma percepção do número de disciplinas voltadas para a formação de professores para atuar na educação de surdos, Cruz aponta que $30 \%$ das análises que provém da existência deste núcleo específico de formação se assemelham.

8 Vale destacar que o curso de especialização oferecido até 2010 ainda apresentava um eixo de disciplinas com abordagem clínica da surdez.
} 
conhecimento da LIBRAS e já entram no curso com um domínio intermediário da língua de sinais.

Outro aspecto importante para o não oferecimento da disciplina de LIBRAS é a obrigatoriedade de turmas mistas, com surdos e ouvintes. Em cada processo seletivo, metade das vagas oferecidas é destinada a interessados surdos. Sendo assim, o convívio com os colegas de turma surdos deve ter proporcionado aos ouvintes um grande contato com a língua e aperfeiçoamento da mesma. Além disso, havia a presença de Tradutores e Intérpretes de Língua de Sinais (TILS) contribuindo na comunicação entre ambos e, consequentemente, na construção da aprendizagem da língua.

O curso de Pedagogia Bilíngue passou por uma reformulação, a partir das análises e estudos feitos pelo corpo docente, e, em 2015, passou a oferecer dentro de sua nova grade curricular a disciplina LIBRAS. Esta alteração é fruto de forte debate sobre o papel do professor bilíngue que ao atuar na educação infantil e nos primeiros anos do ensino fundamental se vê confrontado ao ensino EM Libras e DE Libras. Sendo assim a disciplina passa a ser oferecida em cinco períodos, perfazendo um total de 300 horas. Vale destacar que a exigência do conhecimento prévio da língua de sinais para entrar no curso permaneceu, então a disciplina de LIBRAS não começa o ensino de uma língua, mas ela o aprofunda.

A nova grade do curso traz outras mudanças, direcionando mais algumas disciplinas para a questão cultural e identitária do surdo.

Este novo curso é oferecido em 8 semestres e contém 3320 horas, dentre elas 400 horas de estágio. Percebemos que houve uma diminuição de carga horário, se compararmos com o curso anterior, que oferecia 3480 horas de formação.

Durante as diversas reuniões para reorganização do curso $^{9}$ se priorizou um equilíbrio entre as disciplinas da área da pedagogia, que formam o pedagogo para atuar nos diversos espaços previstos por lei e as disciplinas da área da surdez, que fazem a especificidade desta formação. Segundo vários professores

\footnotetext{
9 Desde 2011 o corpo docente vem estudando e dialogando com a academia e com o corpo discente sobre a fundamentação do curso, seus objetivos e sua organização, logo esta reestruturação não foi feita de forma acelerada e sem análises profundas
} 
do curso, algumas disciplinas do antigo currículo eram repetitivas em suas ementas, e, ainda, outras áreas do conhecimento não eram trabalhadas. Outra questão abordada era a diferença de carga horária entre as disciplinas, aspecto este muito ruim para organização do curso em sua modalidade EAD. Visto isso, resolveu-se padronizar a carga horária das disciplinas em 60 horas, tendo apenas o estágio supervisionado uma carga horária diferenciada de 100 horas, entendendo-se que sua dinâmica também é diferenciada.

Ao analisar a nova grade, usando o mesmo princípio utilizado na análise feita com a grade de 2006, percebemos que 32\% das disciplinas oferecidas estão voltadas especificamente ou em mais de $50 \%$ de seus programas para formação de professores para atuar na educação de surdos. Apesar de ter diminuído um pouco o número de disciplinas especializadas do campo da surdez, esta diminuição não foi significativa e, ao mesmo tempo, encontramos todos os conteúdos previstos nas ementas do currículo de 2006 no currículo de 2015, com o acréscimo da disciplina de Libras. Para entendermos este fato, é importante que ressaltemos que o currículo de 2006 continha um conjunto de 7 disciplinas chamadas "Tópicos Avançados de Âmbito Bilíngue", numeradas de um a sete, que apresentavam em suas ementas propostas abertas, destacando a importância de se construírem pesquisas no campo da surdez. Desta feita, o conteúdo era elaborado por cada professor, para cada turma e a cada semestre, não sendo possível delinearmos os conteúdos presentes neste campo curricular.

O corpo docente deste curso é composto por 39 professores, sendo 34 doutores, 3 mestres ( 1 no último ano do doutorado) e 2 especialistas ( 1 no último ano do mestrado). Do total de professores, 6 são surdos, sendo 4 deles concursados para a disciplina de Libras, que, até o momento, só foi oferecida por professores surdos.

A instituição oferece a todos os professores um curso de Libras, com duração total de 250 horas, dividido em 5 níveis. Além dessa formação, o Departamento de Ensino Superior, ao qual o Curso de Pedagogia Bilíngue está atrelado, oferece cursos de Libras mais focados nos interesses dos professores 
do Ensino Superior ${ }^{10}$. Vale destacar que os professores nunca passaram por teste de proficiência, então não podemos determinar de forma categórica o nível de conhecimento de Libras destes.

Os dados que apresento a seguir estão fundamentados no nível de conforto que os professores apresentam para oferecer seus cursos em Libras ou desenvolver um diálogo, nessa língua, em uma reunião oficial do curso. Segundo estes critérios, $29 \%$ dos docentes tem pleno domínio da Libras, 20\% tem domínio moderado, conseguindo estes desenvolver suas atividades em Libras, mas em ritmo bem mais lento do que em sua língua materna e 51\% ainda necessita de plena atuação de intérpretes de Libras para realizar suas atividades de docência e pesquisa. Estes números demonstram que os docentes em sua maioria não são bilíngues, logo o ambiente linguístico não é fortemente preenchido pela língua de sinais. Em praticamente todos os momentos não oficiais (conversas de corredor, sala de professores, pausa café e outros), nos quais a presença do intérprete não existe, percebemos que a Libras não é utilizada, a não ser que tenha um surdo envolvido diretamente na conversa.

Quanto ao corpo discente, ao analisarmos os dados do Curso de Pedagogia Bilíngue em março de 2018, percebemos que, apesar de oferecer em seu processo seletivo $50 \%$ das vagas para candidatos surdos, o quantitativo de alunos ouvintes é maior do que o quantitativo de alunos surdos, tanto nos dados relativos aos alunos ativos, como no de alunos formados. Segundo dados da secretaria do curso (2017), 30\% são alunos ativos surdos e 70\% são alunos ativos ouvintes. Dentre o grupo de formados $25 \%$ são surdos e $75 \%$ são ouvintes. Podemos vislumbrar alguns fatores para este desequilíbrio. Além das questões sociais que provocam a saída de muitos alunos, sejam estes surdos ou ouvintes, destacaremos algumas questões atreladas ao curso.

Como relatamos ao analisar os docentes do curso, o ambiente linguístico não é o mais confortável para o aluno surdo, visto que este, em grande parte dos momentos, não consegue interagir diretamente com os professores, tendo que

${ }^{10}$ Este curso não é oferecido de forma contínua, apenas quando há disponibilidade de carga horária de uma das docentes de Libras do departamento. 
recorrer aos intérpretes de Libras. Sabemos que esta relação triangular, dificulta a compreensão e em muitos casos desestimula os alunos surdos.

Outro ponto a ser analisado é o quantitativo de materiais em Língua Portuguesa e a frágil compreensão desta língua por boa parte dos alunos surdos. Apesar dos diversos arranjos didáticos propostos pelos professores aos seus alunos surdos, o meio acadêmico ainda não produz material em Libras, o que torna a leitura em LP obrigatória para a aquisição de conhecimentos.

De qualquer maneira, é preciso destacar as especificidades deste Curso de Formação de Professores: currículo voltado para escolarização de surdos; turmas bilíngues; reserva de vagas para surdos e participação de intérpretes de Libras em todas as atividades oficiais do curso. Conforme enfatiza Cruz (2016, p. 109) "Com estas características, o curso do INES protagoniza desde 2006 a oferta de uma formação singular, inovadora, antenada com a luta da 'comunidade surda', de professores e pesquisadores da área."

\section{Institut d'Enseignement Supérieur et de Recherche Handicap et Besoins Éducatifs Particuliers (INS-HEA) - França}

Desde a criação desta instituição em 1954, a mesma oferece curso de formação de professores para atuar na educação especial. Todas essas propostas são oferecidas aos professores já formados, podendo então serem caracterizadas como formação continuada. $\mathrm{Na}$ verdade, percebemos no histórico de propostas de cursos que eles criam primeiramente certificações, e a partir destas, cursos preparatórios para que os candidatos ao certificado adquiram o conhecimento necessário para poderem se submeter aos exames.

Nesta linha de certificações, foi criado em 1963 o Certificado De Aptidão À Educação de Crianças e Adolescentes Deficientes e Inadaptados - CAEI, entretanto, nesse momento, os exames não tratavam da educação de surdos. Apenas em 1966 o CAEI inclui novas opções e, dentre elas, a deficiência auditiva ${ }^{11}$.

\footnotetext{
${ }^{11}$ Nome utilizado no texto da lei.
} 
A formação de professores para trabalhar com alunos surdos não aconteceu, e nem acontece, de forma dissociada da formação de professores para atuar na educação especial, sempre houve um tronco comum na formação, trabalhando áreas como o direito, recursos pedagógicos, relação com a família, dentre outros, e uma área em opção, que, no caso da surdez, surgiu em 1966.

Em 1987, com o advento da proposta da integração escolar, o CAEI se transforma em CAPSAIS - Certificado de Aptidão para Ações Pedagógicas Especializadas e para Adaptação e Integração Escolar. Este também apresenta um tronco comum e opções diversas, dentre elas a área da deficiência auditiva. Ao analisarmos o programa, percebemos que há uma enorme preocupação com o pedagógico, visto que menos de $10 \%$ da formação é consagrada ao campo da saúde. Esse aspecto também é percebido nas discussões acadêmicas sobre educação especial e nos movimentos surdos, nestes anos de 1980.

Outro ponto interessante a ser destacado é o grande bloco de disciplinas e conteúdos na área da linguagem, inclusive um deles consagrado à educação bilíngue, temática que ainda era bem inovadora nesse período.

Esta formação era destinada aos professores do chamado Primeiro $\mathrm{Grau}^{12}$. Ao concluir a formação e obter o certificado, muitos se tornavam responsáveis pela educação especial em suas regiões, sendo este, inclusive, um dos objetivos da formação. Para atender a esse objetivo, a formação tinha também em seu programa disciplinas que versavam sobre integração sócioprofissional, relação com as famílias, questões legais e jurídicas e questões associativas, originando a formação de um profissional para além do espaço da sala de aula.

A formação de professores para preparação do CAPSAIS continha 600 horas (Circulaire no 97-104 du 30 avril 1997), sendo 150 horas de tronco comum, 300 horas de formação específica em duas opções e 150 horas de estágio prático. Toda a formação poderia acontecer em dois ou três anos, de acordo com a organização de alternância entre trabalho e formação, visto que o professor

12 Os professores do Primeiro Grau são os professores da educação infantil e dos anos iniciais do ensino fundamental. 
deveria se ausentar do seu posto de trabalho para participar da formação e um professor substituto deveria ser previsto para sua turma.

A formação específica, desde a criação do CAPSAIS, foi dividida entre o INS-HEA, responsável pelas opções- deficiência auditiva, deficiência visual e deficiência física e motora- e outros centros nacionais de formação. Nessa pesquisa estudamos e analisamos apenas o INS-HEA, visto que este era, e continua sendo, o único responsável pela formação para o exercício do magistério com alunos surdos.

Em 2004, através do Decreto oㅜ 2004-13 de 5 de janeiro, cria-se, em substituição ao CAPSAIS, o Certificado Dde Aptidão Profissional para Apoio Especializado, Ensino Especializado e Escolarização de Alunos Eem Situação Dde Deficiência (CAPA-SH), destinado aos professores do Primeiro Grau. Este mesmo decreto cria o Certificado Complementar para o Ensino Especializado e para Escolarização dos Alunos em Situação de Deficiência (2CA-SH), destinado aos professores do Segundo Grau ${ }^{13}$. Pela primeira vez, encontramos uma iniciativa de formação que contemplasse aos professores das disciplinas específicas, visto que, até então, apenas os professores generalistas que atuam na educação infantil e nos primeiros anos do ensino fundamental eram passíveis de pleitear uma vaga neste percurso de formação. Detectamos, então, um avanço e um alargamento para toda a educação básica da possibilidade de formação para atuar com alunos surdos. Entretanto, os programas de formação oferecidos para obtenção do CAPA-SH e do 2CA-SH eram bem distintos.

Na proposta do CAPA-SH e do 2CA-SH a formação é toda voltada para a área escolhida pelo candidato, sendo assim não há mais tronco comum.

O CAPA-SH oferecia uma formação em 400 horas totalmente voltada para uma especificidade dentro da educação especial, como, por exemplo, no campo da surdez. Dentre estas 400 horas, metade era destinada às práticas pedagógicas (200 horas), 1/4 era destinado a práticas profissionais numa proposta multidisciplinar (100 horas) e 1/4 voltado para as práticas profissionais

\footnotetext{
${ }^{13}$ No sistema francês o Segundo Grau é composto pelo nosso Ensino Fundamental II (Collège) e pelo Ensino Médio (Lycée).
} 
no que concerne ao meio familiar, social e escolar (100 horas). Esta era realizada em um ano escolar.

Já o 2 CA-SH, destinado aos professores do Segundo Grau, oferecia uma formação de 150 horas, também voltada para uma área específica da educação especial. A carga horária era assim organizada: 100 horas de práticas pedagógicas, 25 horas de práticas profissionais numa proposta multidisciplinar e 25 horas de práticas profissionais no que concerne ao meio familiar, social e escolar. De acordo com a organização da escola e do departamento, esta formação poderia ser feita em até três anos ${ }^{14}$.

Ainda em 2004, o INS-HEA recebe a atribuição, a partir da Nota de Serviço n² 2004-105 de 25 de junho, para oferecer formação continuada como: "Aperfeiçoamento de Língua Francesa de Sinais para os Professores Especializados de Primeiro Grau".

Dentre as preocupações nacionais com a formação de professores, destacamos o desenvolvimento da língua de sinais, visando melhorar o processo de comunicação entre professor e aluno surdo, facilitando assim a construção da aprendizagem.

Em 2013, a Lei de Orientação e de Programação para Refundação da Escola da República (2013-595 de 8 de julho) afirmava em seu artigo 1ํำ princípio da inclusão, estabelecendo o direito de cada criança não só de ser escolarizada nas mesmas condições dos outros alunos, mas também de ser escolarizada com estes alunos.

Para responder aos objetivos de inclusão previstos na lei e oferecer um acompanhamento escolar de qualidade para as crianças deficientes incluídas, era necessário repensar a formação dos professores especializados.

A formação oferecida desde 2004, que se organizava por áreas separadas, na qual o professor candidato se inscrevia em apenas uma opção, não atende mais à realidade das escolas francesas, nem dos alunos e suas famílias.

${ }^{14} \mathrm{O}$ programa do curso poderia ser realizado em um ano escolar, caso fosse possível para o docente e sua escola. 
Outra questão foi o aumento de alunos deficientes no Segundo Grau, Já que somente no ano escolar 2015/2016 este aumento foi de 9,6\% (http://enseignants.se-unsa.org, 2016). Para se confrontar com esta realidade, os professores desse nível de ensino participavam de uma formação com carga horária diminuta, de apenas 150 horas, e, como salientamos acima, em apenas um campo da educação especial.

A partir dessa constatação, começou-se um estudo para reformular essa formação, através de uma harmonização entre as formações oferecidas para os professores do Primeiro Grau e do Segundo Grau.

Então, em setembro de 2017, entra em vigor uma nova certificação e, consequentemente, uma nova formação, a partir do Decreto n 2017-169 de 10 de fevereiro, que cria o Certificado de Aptidão Pedagógica para as Práticas de Educação Inclusiva - CAPPEI.

Essa certificação é única para os professores do Primeiro Grau e do Segundo Grau e não é mais separada por áreas, em que o candidato escolhe apenas uma área de formação, que é constituída por módulos. Estes estão organizados de forma a oferecer a todos um tronco comum, com duração de 144 horas, e dois módulos de aprofundamento, neste caso por opção nas áreas da educação especial. Esses módulos estão organizados em duas grandes áreas e os professores/estagiários escolhem uma opção de cada grande área. $\mathrm{Na}$ grande área $A$, os módulos de aperfeiçoamento são: 1) Grande dificuldade em matemática; 2) Grande dificuldade em leitura e escrita; 3) Grande dificuldade em adaptação à escola; 4) Distúrbios psíquicos; 5) Distúrbios específicos da língua e da aprendizagem; 6) Distúrbios das funções cognitivas. E os módulos previstos para a grande área B são: 1) Distúrbios auditivos; 2) Distúrbios visuais; 3) Distúrbios do espectro autista; 4) Distúrbios motores. Cada módulo de aperfeiçoamento tem duração de 104 horas. Ainda está prevista uma inserção prática de 52 horas, perfazendo um total de 404 horas de formação.

No que concerne à área da surdez podemos inferir que há uma perda na formação, visto que no modelo anterior (CAPA-SH e 2 CA-SH) os professores/estagiários participavam de uma formação de 400 horas destinadas exclusivamente para este campo, inclusive com uma parte do tempo dedicado 
ao ensino de LSF. No novo modelo (CAPPEI), a carga horária de formação neste campo ficou reduzida a $1 / 4$ da carga horária, ou seja, 104 horas.

Ao analisar os programas e realizar entrevistas, percebemos que parte da formação oferecida no tronco comum do CAPPEI também era trabalhada no curso anterior, visto que algumas questões legais, pedagógicas e sobre as relações com a família e com a profissionalização podem ser vistas num espectro mais geral; mesmo assim, consideramos que houve uma perda na formação. $O$ ponto mais relevante desta queda na formação é a inexistência de curso de LSF.

A circular 2017-026 de 14 de fevereiro, que orienta a implantação do CAPPEI, determina que para "os candidatos que se destinam ao exercício do magistério com alunos com distúrbio da função auditiva devem justificar o nível A1 de língua de sinais francesa (LSF)". A opção desta política pública foi de demandar uma formação prévia - muito inicial ainda, visto que o nível A1 é o primeiro de seis níveis, que não habilita o professor a ensinar em LSF - e não a de formar dentro da própria especialização professores bilíngues ou, pelo menos, com um conhecimento da língua que lhes permita se comunicar com seus alunos surdos sinalizantes.

Como esse é o primeiro ano desse modelo de formação, ainda é cedo para fazermos uma avaliação dos ganhos e das perdas do CAPPEI para as práticas pedagógicas dos professores.

O corpo docente do pólo surdez é composto de 7 professores, sendo 3 professores ouvintes (dois doutores e um doutorando) e 4 professores surdos (todos com Master ${ }^{15}$ ). Segundo informações da própria equipe do pólo, 6 professores sinalizam muito bem e 1 professor tem nível intermediário de LSF. Podemos dizer que o ambiente linguístico dentro do pólo é extremamente favorável aos surdos e à comunicação em sua própria língua.

Por outro lado, a instituição vem tentando sensibilizar outros professores e funcionários, no intuito de expandir este espaço de convivialidade em LSF, e , para tal, oferece para todos os funcionários que assim o desejarem o curso de LSF em seu horário de trabalho.

\footnotetext{
${ }^{15}$ Em muitos casos, o master francês tem equivalência ao mestrado no Brasil.
} 
Quanto aos professores/estagiários, não há registro de surdos inscritos, visto que apenas os professores da educação nacional podem realizar esta formação e o número de professores surdos concursados, segundo dados dos entrevistados do pólo, ainda é bem pequeno e se restringe aos docentes da disciplina de LSF, que foi incluída como possibilidade de segunda língua em algumas escolas de fundamental II e de ensino médio.

A taxa de evasão do curso é extremamente baixa, visto que a concorrência para fazer o curso é grande e que eles o realizam durante o ano letivo.

O curso está assim organizado: O professor/ estagiário continua responsável por sua turma enquanto docente no ano de formação e, ao longo do ano, ele faz quatro saídas de duas semanas cada, nesses momentos de formação, a Academia de Ensino se programa para ter nas turmas um professor substituto, principalmente para as turmas do Primeiro Grau. Os professores de Segundo Grau são raramente substituídos, ficando seus alunos sem aula durante 8 semanas no ano letivo. Esse é um problema apresentado pelos entrevistados, que apontam pouco empenho da Educação Nacional para substituir o professor e, assim, manter o ritmo e a qualidade do ensino.

Para o professor/estagiário, essa proposta de alternância entre atuação e formação é muito interessante, pois ele leva a sua realidade para o espaço da formação e, no sentido contrário, ele leva os novos conhecimentos para o seu espaço de sala de aula.

Como já dito anteriormente, a parte do tronco comum é oferecida pelas academias de ensino espalhadas pelos departamentos da França, mas a parte específica da surdez é oferecida apenas no INS HEA, que se localiza na região parisiense. Para viabilizar a estadia dos professores durante pelo menos 4 semanas do ano letivo na região parisiense, o INS HEA oferece alojamento para 40 professores, bem como refeitório. Na rotina de qualquer pessoa não é fácil se afastar de suas obrigações familiares e profissionais, e se ainda tivessem um custo elevado para fazê-lo, isso inviabilizaria a formação para boa parte dos docentes. Sendo assim, o oferecimento de estadia e alimentação é parte integrante do processo de formação. 
Percebemos então, que apesar de ainda atender um número muito pequeno de docentes, o governo francês vem pensando em políticas de formação destes para trabalhar com a educação de surdos.

\section{Considerações finais}

Trouxemos aqui algumas reflexões propiciadas pela pesquisa, a título de conclusões, sempre provisórias, e indicações de novas questões para a pesquisa.

A pesquisa teve como principal objetivo analisar a formação de professores para atuar na escolarização de surdos nos modelos brasileiro e francês.

No que se refere às propostas de formação, evidenciaram-se modelos bem distintos, visto que na realidade brasileira a formação é oferecida como uma formação inicial universitária, enquanto que na França ela é oferecida como formação continuada para quem já exerce a profissão e se encontra frente à realidade de escolarizar alunos surdos.

Quanto ao lugar concedido à língua de sinais, percebe-se, num primeiro momento, a experiência brasileira não vislumbrou a necessidade de oferecimento da mesma, entendendo que os alunos já ingressavam no curso com conhecimento prévio desta, mas, ao longo do tempo, foi-se percebendo que esse conhecimento era diverso e não satisfatório e, assim, uma carga horária relevante foi incluída na grade do curso. Já a experiência francesa no início apresentava a língua de sinais como uma das disciplinas obrigatórias de sua formação, mas, no modelo atual, implementado em 2017, a língua de sinais não é mais oferecida e essa ausência é vista pelos próprios professores do pólo surdez como uma fragilidade da formação.

Ambas as formações destacam que apenas o conhecimento da língua de sinais não é suficiente para o processo de escolarização de surdos, sendo assim, valorizam em seus programas aspectos ligados à identidade surda e cultura surda.

A pesquisa revelou que existe um movimento de mudança e reflexão sobre a formação de professores para atuar na escolarização de surdos, algumas 
políticas públicas vêm sendo implementadas em ambos os países e os indivíduos diretamente ligados começam a ter voz, sejam estes professores ou comunidade surda.

\section{Referências bibliográficas}

ANDRÉ, M. Formação de Professores: a constituição de um campo de estudos. Em: Educação, Porto Alegre, v. 33, n. 3, p. 174-181, set./dez. 2009

ANTUNES, A. L.; NASCIMENTO, M. das G. C. de A. A profissão docente e a educação de surdos: demandas e dificuldades. In: IV EDIPE - Encontro Estadual de Didática e Prática de Ensino - Para uma realidade complexa, que escola, que ensino? Goiânia, Brasil, 2011.

BRASIL. Ministério da Educação. Secretaria de Educação Especial. Decreto no 5.626, de 22 de dezembro de 2005. Regulamenta a Lei no 10.436, de 24 de abril de 2002 (Dispõe sobre a Língua Brasileira de Sinais - LIBRAS e dá outras providências).

BRASIL. Decreto 7.612. Diário Oficial da União - Seção 1 - 18/11/2011, Página 12 (Publicação Original). Institui o Plano Nacional dos Direitos da Pessoa com Deficiência - Plano Viver sem Limite, 2011.

BUENO, J. G. S. Educação inclusiva e escolarização dos surdos. Integração, Brasília - DF, v. 13, n.23, p. 37-42, 2001.

CAMPELLO, A. R.; REZENDE, P. L. F. Em defesa da escola bilígue para surdos: a história de lutas do movimento surdo brasileiro. Educar em Revista, Curitiba, n.2, p.71-92, 2014.

CRUZ, M. R. Experiências instituintes na formação de professores de surdos no INES. Niterói: UFF. Tese de Doutorado, 2016

DIAS, S. Educação e inclusão: projeto moral ou ético. Educação e Subjetividade, Faculdade de Educação da PUCSP, Ano 1, n.02, p.17- 42, 2006.

FRANÇA. Circulaire n 1997-104 du 30 avril 1997 Formations préparant à l'examen pour l'obtention du CAPSAIS, 1997.

FRANÇA. Décret n`2004-13 du 5 janvier 2004 créant le certificat d'aptitude professionnelle pour les aides spécialisées, les enseignements adaptés et la scolarisation des élèves en situation de handicap et le certificat complémentaire pour les enseignements adaptés et la scolarisation des élèves en situation de handicap, 2004. 
FRANÇA. LOI n 2013-595 du 8 juillet 2013 d'orientation et de programmation pour la refondation de l'école de la République, 2013.

FRANÇA. Décret n 2017-169 du 10 février 2017 relatif au certificat d'aptitude professionnelle aux pratiques de l'éducation inclusive et à la formation professionnelle spécialisée, 2017.

FRANÇA. Circulaire ${ }^{\circ}$ 2017-026 du 14 février 2017 Circulaire relative à la formation professionnelle spécialisée et au certificat d'aptitude professionnelle aux pratiques de l'éducation inclusive (Cappei), 2017.

FRANCO, M. Educação superior bilíngue para surdos: o sentido da política inclusiva como espaço da liberdade: primeiras aproximações. Rev. bras. educ. espec. [online], vol.15, n.1, 2009.

GATTI, B.; BARReTtO, E. S. S.; ANDRÉ, M. E. D. A. Políticas docentes no Brasil: um estado da arte. Brasília: UNESCO, 2011.

GEFFROY V., \& Le Roux F. L'enseignement bilingue pour sourds en France vu sous l'angle de la didactique des langues. MOARA Revista Eletrônica do Programa de Pós-Graduação em Letras, n. 45, 2016.

INES. Projeto Pedagógico do Curso Bilíngue de Pedagogia (Libras-Lingua Portuguesa Escrita). Rio de Janeiro, 2006.

INES. Projeto Pedagógico do Curso de Pedagogia Bilíngue (Libras-Lingua Portuguesa Escrita). Rio de Janeiro, 2015.

JANUZZI, G. M. A educação do deficiente no Brasil: dos primórdios ao início do século XXI . Campinas: Autores Associados, 2004.

NASCIMENTO, S. P. de F. do; COSTA, M. R. Movimentos surdos e os fundamentos e metas da escola bilíngue de surdos: contribuições ao debate institucional. Educar em Revista, Curitiba, n.2, p.159-178, 2014.

NOVOA, A. Desafios do trabalho do professor no mundo contemporâneo. Palestra proferida no SIMPRO - SP, 2007. Disponível em:<http://www.sinprosp.org.br/arquivos/novoa/livreto_novoa.pdf>. Acesso em: set. 2017.

PEDREIRA, S. Porque a palavra não adianta: um olhar sobre a inclusão escolar de surdos/as numa perspectiva intercultural. Em XIV Encontro Nacional de Didática e Prática de Ensino: trajetórias e processos de ensinar e aprender: lugares, memórias e culturas. CD ROM 1 Anais. Porto Alegre : ENDIPE, 2008. 
SACKS, O. Vendo vozes. Uma viagem ao mundo dos surdos. São Paulo: Companhia das Letras, 1998.

SILVA, V. et al. Educação de surdos: Uma Releitura da Primeira Escola Pública para Surdos em Paris e do Congresso de Milão em 1880. In: QUADROS, R. M. (Org). Estudos surdos I. Petrópolis, RJ: Arara Azul, 2006.

SKLIAR, C. (Org.). Atualidade da educação bilíngue para surdos. Porto Alegre: Mediação, vol. I-II, 1997.

SKLIAR, C. B.; LUNARDI, M. L. Estudos surdos e estudos culturais em educação: um debate entre professores ouvintes e surdos sobre o currículo escolar. In: LACERDA, C. B. F.; GÓES, M. C. R. (Orgs.). Surdez: processos educativos e subjetividade. São Paulo: LOVISE, 2000, p. 11-22.

STOKOE, W. C. Sign Language structure: an outline of the visual communication system for the American deaf. Buffalo: Buffalo University, 1960.

WALSH, C. Interculturalidade Crítica e Pedagogia Decolonial: In-surgir, re-existir e re-viver. In: CANDAU, V. M. (org.) Educação Intercultural na América Latina: entre concepções, tensões e propostas. Rio de Janeiro: 7 Letras, 2009.

ZEICHNER, K. M. Repensando as conexões entre a formação na universidade e as experiências de campo na formação de professores em faculdades e universidades. Educação, Santa Maria, v. 35, n. 3, p. 479-504, set./dez. 2010.

\footnotetext{
Sobre a autora

Yrlla Ribeiro de Oliveira Carneiro da Silva

Pós Doutorado em Educação (em curso), Université Descartes Paris (2017/2018). Doutora em Educação pela UNICAMP (2009). Mestre em Ciências da Educação pela Université René Descartes Paris V - Sorbonne (1997). Possui graduação em Pedagogia também pela Université René Descartes Paris V - Sorbonne (1995). Foi professora das séries iniciais do Ensino Fundamental e das disciplinas pedagógicas do Ensino Médio na modalidade Normal da rede pública de ensino do Estado do Rio de Janeiro (1990 - 2007). Atuou também no Conselho Estadual de Educação do Rio de Janeiro, como assessora técnica. Atualmente é Professora do Curso Bilíngue de Pedagogia do Instituto Nacional de Educação de Surdos (INES). Integra o grupo de estudos e pesquisas sobre profissão e formação docente - GEPROD, UFRJ.
} 